\title{
Accountability for Social impact: A Bricolage Perspective on Impact \\ Measurement in Social Enterprises
}

\author{
Greg Molecke ${ }^{a} \&$ Jonatan Pinkse ${ }^{b^{*}}$ \\ Journal of Business Venturing, Published online \\ ${ }^{\mathrm{a}}$ ESSEC Business School \\ 3 avenue Bernard Hirsch \\ CS 50105 Cergy \\ 95021 Cergy-Pontoise Cedex \\ France \\ Tel.: +33(0)134433000 \\ E-mail: gregmolecke@gmail.com
}

${ }^{\mathrm{b}}$ Alliance Manchester Business School, University of Manchester, Booth St W, Manchester M15 6PB, United Kingdom

Tel: +44 (0) 1612757375

E-mail: jonatan.pinkse@manchester.ac.uk

* Corresponding author 


\begin{abstract}
To fulfill external accountability expectations social impact measurement has become an important practice for social enterprises. Yet, the ambiguity around social impact and its measurement leads to a friction amongst stakeholders involved in a social enterprise. Based on interviews with small-tomedium-sized social enterprises, this paper investigates how social entrepreneurs handle the increasing pressure to measure social impact with formal methodologies through a bricolage lens. The findings show how social enterprises combine material and ideational bricolage as well as seek to delegitimize formal methodologies to increase the legitimacy of their bricolaged approaches for social impact measurement.
\end{abstract}

Key words: Social entrepreneurs; Social impact measurement; Bricolage; Accountability 


\section{Introduction}

To fulfill external accountability expectations, to attract financial and other types of support, and to gain better insights in how to optimize operations, social impact measurement has become an important practice for social enterprises (Ebrahim, Battilana, \& Mair, 2014; Ebrahim \& Rangan, 2014; Nicholls, 2009). Yet, this practice is contested (Choi \& Majumdar, 2014; Mair \& Martí, 2006; Paton, 2003). There is ambiguity, for example, about the nature of social impact (Choi \& Majumdar, 2014); the relationship between social enterprises' interventions and social impact (Ebrahim \& Rangan, 2014); and the methodologies to measure social impact (Nicholls, 2009). An underlying reason for this ambiguity is that, in contrast to accounting conventions for financial performance assessment, there are no generally agreed-upon methodologies or units for social impact measurement (Ebrahim et al., 2014; Kroeger \& Weber, 2014; Nicholls, 2009). Many competing methodologies for social impact measurement exist, each with its own strengths, weaknesses, and purposes (McLoughlin et al., 2009). Moreover, it has been argued that social enterprises' accountability to multiple stakeholders with disparate expectations and understandings is a relatively more critical problem than it is for for-profit firms (Ebrahim et al., 2014). Social enterprises thus feel compelled to show different evaluations of their social impact to their different stakeholders.

The ambiguity around social impact and its measurement leads to frictions within and among the various different stakeholders involved in a social enterprise. On the one hand, the trend toward the rationalization and marketization of the social sector (Ebrahim et al., 2014; Eikenberry \& Kluver, 2004) has led funders such as foundations, governments and other types of impact investors, as well as social entrepreneurs themselves, to increasingly value and expect formal measurements of social impact. Such formal methodologies ofr social impact measurement aim to create objective and empirically-based measures that capture the social impact of an organization, often with a goal of increasing standardization, verifiability, and accountability. By importing performance measurement and reporting practices from accounting and finance, funders and social enterprises aim to replicate the efficiency and accountability that such practices have afforded for-profit organizations to better run their organizations and to optimize their funding decisions (Brest, Katz, Peeler, \& Stangler, 2012; Ebrahim \& Rangan, 2014; Kroeger \& Weber, 2014; Nicholls, 2009; Rourke, 2014). On the other 
hand, attempts to integrate formal impact measurement into the social sector has revealed great challenges (Ebrahim \& Rangan, 2014). As Emerson (2003: 40) argued, 'any who advocate the social sector be held to greater accountability and reporting on the progress achieved toward the attainment of societal goals are told in no uncertain terms that, indeed, "some things simply can't be measured and social value is one of them"'(Emerson, 2003: 40). While there is myriad of methods to measure social impact, the lack of conventions makes accountability to multiple stakeholders and for multiple purposes challenging (Ebrahim et al., 2014). Practitioners seem to share an unease about social impact measures not capturing their 'true impact' and doubt the effectiveness of social impact measurement to improve the outcomes of their interventions (Ebrahim \& Rangan, 2014). Since social enterprises 'purposely locate their activities in areas where markets function poorly' (Di Domenico, Haugh, \& Tracey, 2010: 683), they also face severe resource constraints that can hinder the practice of social impact measurement (Nicholls, 2009). While the friction inherent in social impact measurement is well established in the literature (Ebrahim \& Rangan, 2014; Emerson, 2003; Kroeger \& Weber, 2014; Nicholls, 2009), less well understood is how social enterprises contend with this friction.

Based on interviews with small-to-medium-sized social enterprises, we investigate how social entrepreneurs handle the increasing pressure to measure social impact with formal methodologies. As is evident from the extant literature (Ebrahim \& Rangan, 2014; Emerson, 2003; Nicholls, 2009), social enterprises do not seem to unquestioningly comply with this pressure. Rather, they seek to balance the benefits of using formal methodologies with the costs of developing unfamiliar skills and redirecting attention and resources away from activities for venture growth (Rourke, 2014). Besides, as noted, doubts have been raised about the validity and usefulness of formal methodologies for social entrepreneurs' and their stakeholders' decision-making (Ebrahim \& Rangan, 2014; Holma \& Kontinen, 2011; Mueller-Hirth, 2012). Hence, social entrepreneurs tend to approach social accountability demands in a critical fashion, using interpretive flexibility to balance these demands. In line with previous research (Nicholls, 2009), we expect social entrepreneurs to use bricolage for social impact measurement, consistent with their activities for value creation (Di Domenico et al., 2010). The concept of bricolage refers to making do with at-hand resources (Baker \& Nelson, 2005; LéviStrauss, 1962) and has become an important explanation for how social enterprises engage in resource 
acquisition and problem solving (Desa \& Basu, 2013; Di Domenico et al., 2010; Mair \& Marti, 2009; Zahra, Gedajlovic, Neubaum, \& Shulman, 2009). In the context of social impact measurement, bricolage suggests that social enterprises use existing methodologies 'strategically to support their various mission objectives with key stakeholders' (Nicholls, 2009: 756).

In investigating social enterprises' strategic handling of accountability demands through a bricolage lens, the paper makes three main contributions to the literature. First, we show that social enterprises use elements of material and ideational bricolage simultaneously for the practice of social impact measurement (cf. Baker \& Nelson, 2005; Lévi-Strauss, 1962; Mair \& Marti, 2009). The social entrepreneurs not only show evidence of material bricolage by using data they have at hand, but also of ideational bricolage by selectively using and modifying ideas behind the formal methodologies available to them while partly rejecting these as well (Carstensen, 2011). Second, we show that ideational bricolage involves a process of targeted delegitimization of stakeholders' preferred conceptions of social impact and its measurement. Social entrepreneurs' choice of ideational bricolage for social impact measurement rather than existing methodologies reflects a refusal to be constrained by limitations and critically enact their resource environment (Baker \& Nelson, 2005; Di Domenico et al., 2010), in this case the relationship with funders. The social enterprises in our study perceive the demands for formal social impact measurement as a limitation and in response 'test institutionalized definitions of orthodox practice' (Baker \& Nelson, 2005: 335). We contend that delegitimization of existing practices is a key component of bricolage in the context of social enterprise, as it allows the entrepreneurs to create space for new ideas about what social impact means in their specific context (cf. Carstensen, 2011). Third, we contend that by using delegitimization as part of bricolage, social entrepreneurs attempt to change the development of social impact measurement from borrowing performance measurement and reporting practices from accounting and finance to blending these with their own ideas of social impact (Oswick, Fleming, \& Hanlon, 2011). Social entrepreneurs do not merely criticize formal methodologies because they do not embrace the idea that formal social impact measurement represents the future of the social sector; their delegitimization rather serves the purpose of creating dissonance in these methodologies to use them in a way that fits their own understanding of social impact. 


\section{Social Impact Measurement: A Contested Management Practice}

As noted, there is a friction inherent in social impact measurement between the multiple stakeholders involved in a social enterprise with regard to their understanding of the nature of social impact and how it can be measured (Choi \& Majumdar, 2014; Nicholls, 2009). A root cause of this friction is the lack of definitional clarity on social impact that also exists in the literature (Ebrahim \& Rangan, 2014). According to Roche (1999: 21), impact refers to 'significant or lasting changes in people's lives, brought about by a given action or series of actions.' Roche emphasizes that an impact need not have a lasting change in people's lives, as long as it is significant. However, he conflates the concepts of impact and outcome. Defining impacts as 'lasting changes in the lives of individuals' and outcomes as 'lasting results achieved at a community or societal level,' Ebrahim and Rangan (2014: 120) instead stress the different levels of analysis of the two. Accordingly, they argue that impact should be measured on the level of the funder not of the social enterprise because only funders have the scope to affect communities or societies. Notwithstanding their different interpretations, both studies juxtapose impact and outcome with outputs, which refer to the products or services a social intervention generates, and the immediate effect they have. To illustrate the above logic, for a social enterprise that provides low-cost cataract surgeries, restored sight for patients would be an output, whereas the immediate life-changes experienced by the person whose sight has been restored would be outcomes. The overall repercussions of people having their eyesight restored, both individually and to broader society, would be the impact (Millar \& Hall, 2013).

Another reason for a friction between stakeholders with regard to formal social impact measurement is the underlying assumption within most methodologies of a 'causal chain' or logicmodel' running from inputs to activities, outputs, outcomes and impacts, respectively (Ebrahim \& Rangan, 2014). The underlying logic of such methodologies is 'an explicit theory or model of how the program causes the intended or observed outcomes' (Rogers, Petrosino, Huebner, \& Hacsi, 2000: 5) and then subdivides this theory into stages that link together to explain each part of the process that transforms inputs into impacts (Chen \& Rossi, 1983; Donaldson, 2012; Ebrahim et al., 2014; Liket, 
Rey-Garcia, \& Maas, 2014). In contrast, practitioners with experience in implementing such formal methodologies often stress the causal ambiguity of this chain; they contend that impacts are difficult to understand with precision, much less calculate (Ebrahim \& Rangan, 2014; Emerson, 2003). Exogenous factors outside of the enterprise's control may neutralize or counteract the intended effect of an intervention (or, there might not have been a causal relation to begin with). While outputs are largely controlled by the enterprise and can thus be measured, outcomes and impacts are more difficult to isolate and account for. Social enterprises operate in an ecosystem, including other social enterprises, businesses, and aid organizations, each of which may contribute to or interact with each other's impacts. Attributing impact to a specific actor can thus be very difficult (Ebrahim \& Rangan, 2014; Roche, 1999).

A friction between stakeholders also arises due to difficulties to translate rich, experiential information into simple, parsimonious measures of social impact. That is, there is a trade-off in social impact measurement between creating accounts that capture the experiential richness, variance, and flexibility of social entrepreneurs' interpretations and accounts that are easily transferable and interpretable for funders. Inherent in this friction is an element of the different geographic and occupational standpoints of stakeholders involved. Social entrepreneurs' evaluation of impact has a vast experiential element to it - their daily experiences provide them with rich contextual information (Ebrahim \& Rangan, 2014). Yet, much of this experience and context can be difficult to convey to other stakeholders (Putland, 2008; Simon, 1987). Funders' direct experience, for example, may be limited to short visits or lacking altogether. Geographic and cultural distance restricts them from grasping the full significance and context of a social enterprise's intervention and affects how they interpret information about the intervention (David \& Fahey, 2000). For funders, it is difficult to know whether personal and anecdotal data has been cherry-picked or skewed. Consequently, they may disqualify experiential information in attempts to avoid misrepresentation.

Finally, while funders tend to ask for the use of formal social impact measurement, a friction arises because it is not obvious which methods would be their preferred ones. Different stakeholders may prefer different measures (Ebrahim \& Rangan, 2014). Social impact measurement is a burgeoning field, but it is full of alternatives and still in the process of developing conventions and 
standards (Kroeger \& Weber, 2014; McLoughlin et al., 2009; Rourke, 2014). Foundational research has developed methods to use economic or financial techniques to convert impacts into quantitative formats, such as contingent, stated and revealed preferences (Carson \& Hanemann, 2005; Haab \& McConnell, 2002; Hanemann, 1994), estimations of decision utility (Dolan \& Kahneman, 2008; Kroeger \& Weber, 2014), and 'willingness to pay' or 'willingness to accept' (Adamowicz, Louviere, \& Williams, 1994). Besides, there are many methods to value social and environmental impact (Ebrahim \& Rangan, 2014; Hubbard, 2009; Olsen \& Galimidi, 2008), including modified versions of conventional business tools, such as Social Return on Investment (SROI) (Haab \& McConnell, 2002; Millar \& Hall, 2013). Other methods use customized measures for specific types of impact, including indexes and scorecards such as the Grameen Foundation's 'Progress out of Poverty Index' (Toohig, 2007) or the Impact Reporting and Investment Standards (IRIS) catalogue of impact measurement metrics. Some methods focus less on the outcomes achieved, but rather on the efficiency and validity of the activities a social enterprise performs to generate social impact. These include methods based on logic models and theories of change (Rogers et al., 2000; 2006), participatory appraisals (Chambers, 1994), social accounting and audit (Gray, 2001), and popular charity comparison tools which compare an organization's use of funds for program delivery versus overhead and fundraising expenses. Finally, experimental methods (e.g. randomized control trials) have been employed to assess outcomes and impacts of interventions (Banerjee, Banerjee, \& Duflo, 2011). This variety of methodologies can lead to a paradox of choice for individual stakeholders and friction among them in deciding which method to use (Ebrahim \& Rangan, 2014). Moreover, there will be different motives behind stakeholders' preferences for particular methodologies: e.g., gaining insight to improve operations, choosing which organizations to fund in order to optimize the return on a social investment portfolio (Frumkin, 2003; Nicholls, 2009), creating a symbolic object designed to establish legitimacy (Fisher, Kuratko, Bloodgood, \& Hornsby, 2017; Nicholls, 2009; Power, 2003), or promoting one's own reputation (Moss, Short, Payne, \& Lumpkin, 2011).

Taken together, then, the ambiguity of social impact and its measurement in terms of the definition, the logic of the chain leading from inputs to impacts, the translation of complex interventions into parsimonious accounts, and the many methodologies available is a double-edged 
sword. On one hand, the ambiguity creates frictions between the multiple stakeholders involved. Given these frictions, the social entrepreneurs may find that implementing formal methodologies limits rather than improves their ability to measure social impact by predefining what data should be used, assuming a causal logic that seems questionable, defining social impact in ways misaligned with their own views, or recommending actions that take them away from their mission (Battilana \& Dorado, 2010; Ebrahim et al., 2014). On the other hand, the ambiguity gives social entrepreneurs a considerable degree of interpretive flexibility (Nicholls, 2009). This flexibility, however, may only extend to ways of measuring social impact that are seen as compatible with the rationalization and marketization of the social sector (Ebrahim et al., 2014; Eikenberry \& Kluver, 2004), such as those that borrow performance measurement and reporting practices from accounting and finance (Brest et al., 2012; Kroeger \& Weber, 2014; Nicholls, 2009; Rourke, 2014). Thus, social entrepreneurs still need to achieve some autonomy in how they approach social impact measurement in order to construct measures that reflect their understandings and stay true to their social mission (Lumpkin, Moss, Gras, Kato, \& Amezcua, 2013). To better understand how social entrepreneurs contend with this interpretive flexibility inherent in social impact measurement (Nicholls, 2009), we employ a bricolage lens (Baker \& Nelson, 2005; Lévi-Strauss, 1962).

\section{A Bricolage Approach to Social Impact Measurement}

Bricolage takes a social constructionist view of an organization's environment (Baker \& Nelson, 2005). It emphasizes that entrepreneurs do not simply accept the limitations set upon them but instead show critical agency in enacting their environment (cf. Weick, 1988). Extant work on bricolage in entrepreneurship focuses on the enactment of resource environments, asking how it is possible that some entrepreneurs are able to create something out of nothing (Baker, 2007; Baker \& Nelson, 2005; Di Domenico et al., 2010). Social entrepreneurs (and nonprofits more generally) have been identified as resorting to bricolage for resource acquisition to reduce costs or their dependence on others (Di Domenico et al., 2010; Gras \& Mendoza-Abarca, 2014; Mair \& Marti, 2009). Following previous work on social entrepreneurship (Desa \& Basu, 2013; Mair \& Marti, 2009), we make a 
distinction between material and ideational bricolage that Lévi-Strauss (1962) already suggested in his original work (Baker, 2007).

Material bricolage refers to the "process through which people use and combine the various resources they have "at hand" as a means of finding workable-if typically imperfect-approaches to a wide variety of problems and opportunities' (Baker, 2007: 697). Studies on material bricolage show how traditional goal-based approaches to product design - whereby firms design a product and then seek the most advantageous resources to construct it - often failed as the costs of acquiring the material resources needed to properly construct it outstrip the value it may generate (Baker \& Nelson, 2005; Garud \& Karnøe, 2003). Social enterprises are known to rely on material bricolage, as they are frequently observed forsaking the goal of creating a specific product and focusing instead on creating whatever product is possible using at-hand resources (Desa \& Basu, 2013; Di Domenico et al., 2010). Social impact measurement also has a material level, as it relies on the collection of data about outcomes and impact of social interventions. Social entrepreneurs are likely to use bricolage for this purpose, and thus resort to using imperfect data, because their activities in poorly functioning or underserved markets makes data collection a significant challenge (Di Domenico et al., 2010).

We argue that social impact measurement also has an ideational level. Ideational bricolage refers to the process by which organizations 'recombine elements of older myths to create new myths serving new functions' (Baker, 2007: 697). Mair and Marti’s (2009) study shows, for example, how social entrepreneurs 'made-do' with customs and religious beliefs that were prevalent in the local environment. By borrowing and repurposing these existing customs and beliefs, the entrepreneurs ensured that local stakeholders accepted their activities to reduce poverty. Through an ideational bricolage lens, social impact measurement is seen as an ideational product that does not in itself create value, but helps social entrepreneurs and stakeholders understand the value created. It thus fits the view of social impact as being socially constructed (Nicholls, 2009; Paton, 2003). Ontologically, social impact is constructed both cognitively by each social entrepreneur and stakeholder individually and socially through a negotiation amongst them. As Paton (2003: 5) contends, 'for social enterprises (particularly) performance is not some underlying attribute that exists and can be known independently of the people centrally involved in and concerned about that organization. Performance 
is what those people more or less agree, implicitly or explicitly, to be performance, what they have in mind when they use the term.' Ideational bricolage implies that social entrepreneurs have the autonomy to cognitively construct and reconstruct social impact to be accountable to multiple stakeholders with disparate expectations and understandings of the social enterprise. As the different stakeholders' expectations tend to be incongruent, social entrepreneurs will have to negotiate amongst them to achieve consensus on how and what to measure, or make strategic decisions which stakeholders to appease and disappoint (Nicholls, 2009). Hence, to stay true to their social mission (Lumpkin et al., 2013), social entrepreneurs face the challenge of finding ways to recombine elements of what social impact means that derive from or resonate with the methodologies for social impact measurement available to them (cf. Carstensen, 2011).

Overall, it is clear from the existing literature on social impact measurement that applying formal methodologies can be challenging as there are many frictions between social enterprises and stakeholders regarding how to measure social impact (Ebrahim \& Rangan, 2014; Nicholls, 2009). Despite Nicholls' (2009) first efforts in conceptualizing social impact measurement as bricolage, much remains to be understood about the actual process of bricolage in this context. It is not clear how social entrepreneurs use and combine material and ideational bricolage; how they bricolage multiple ideas together that might be in tension with each other; and how bricolage functions to legitimate the way social entrepreneurs create social accounts. In the remainder of the paper, we examine these issues in more detail based on interviews with social entrepreneurs active in small-tomedium-sized organizations.

\section{Data and Methods}

Our aim is to study the approaches social entrepreneurs take to engage the frictions inherent in accounting for social impact. As such, a qualitative, inductive methodology best lends itself to our questions (Edmondson \& McManus, 2007). Responses to frictions would be strongest and clearest in situations where the frictions themselves are strongest and most central within an organization. Social enterprises fit this description particularly well. Their hybrid organizational form is a well-noted 
nexus of frictions in the accountability practices, priorities, and conventions between their market and non-market sides (Ebrahim et al., 2014). Further, those working in base-of-the-pyramid and economically developing environments frequently face tensions between the developing environments where the beneficiaries of their operations reside and the developed environments where their funding comes from. This leads to or exacerbates a host of tensions related to culture, geography, technology, communication challenges, and tensions within the wicked problems they are attacking themselves.

We investigated the accountability practices of 22 social enterprises whose primary mission was to aid the extremely poor in developing countries and who all used market-based funding mechanisms to start and grow their enterprise. Since our goal was to look at an enterprise's ways of engaging and responding to the frictions inherent in social impact measurement, we also wanted to focus on periods in their lifecycle when they were initially forming their responses to these frictions. This meant looking at relatively newer firms that were either starting up or searching for their first round of scaling-up funding. These enterprises were having to create and revise their responses to new stakeholders and were in the process of developing and refining their social impact measurement. While larger and more experienced firms had more net experience, they were more temporally distant from the periods when their social impact measurements were originally developed. To gain additional perspective and to triangulate the data from the social enterprises, one additional interview was carried out with an impact investment firm that specializes in funding social enterprises. In total we conducted 23 interviews, but in some interviews there was more than interviewee present.

After a small initial group of social enterprises was found through internet searches and personal networks, subsequent ones were approached iteratively in relation to the emerging dimensions of our data (Corbin \& Strauss, 2014; Sandelowski, Holditch-Davis, \& Harris, 1992). For example, certain early interviews suggested that entrepreneurs working in rural areas might need to approach their social impact accounts differently because of the more transient, isolated, and insular nature of many of their beneficiaries. We then sought out additional social entrepreneurs for inclusion in our study to ensure we 'filled out' and achieved representative coverage (Coyne, 1997; Sandelowski, 1995) of both sides of this urban vs. rural setting dimension. In this approach, theoretical sampling selection cannot be predetermined in advance and instead emerges to "lead the 
researcher to more sampling in particular dimensions' (Coyne, 1997: 624; Schatzman \& Strauss, 1973). Our iterations ultimately resulted in several theoretically relevant categories: geographical region, urban vs. rural setting, industry, founders' country of origin, organizational status, and basic business model. Our focus, however, was on seeking common patterns that might fit across both sides of these dimensions to understand 'how diverse factors configure as a whole' (Sandelowski, 1995: 182), since these can be generalized into universal theoretical models and can build propositions for testing in future studies (Yin, 2003). Table 1 details the social enterprises that were interviewed.

Insert Table 1 about here

We began by interviewing one or two members of each enterprise, usually a founder and/or key employee who reported to the founder, via phone or internet video calls. A semi-structured format was used, starting with a standard list of questions to probe the enterprise's social impact measures, how those measures arose, key challenges or issues they experienced, key insights or benefits that they gained from accomplishing the measurement, and the roles and demands of internal and external constituencies in shaping the impact measures. On average, interviews lasted approximately 1 hour. Additionally, we collected current and archival secondary data for each enterprise regarding the social impact accounts they created, including: website materials, impact reports/statements, annual reports, business plans, newspaper clippings, white papers/other documents they have published related to impact, posted interviews, other marketing documents, and Facebook wall posts. These documents added rich details to social impact accounts, giving evidence of how social impact accounts were ultimately created, and allowed comparisons with the interview data.

Once completed, the interviews were transcribed and analyzed using Atlas.ti 7, and, later, Nvivo10 software. We began coding inductively, using first-order, in vivo codes based on concepts and themes expressed directly in the statements of the interviewees (Corbin \& Strauss, 2014; Van Maanen, 1979). Several hundred codes arose from this initial coding due to its granular and descriptive nature. These codes did not have clear conceptual boundaries between them, and so an initial process of consolidating and refining codes occurred. Codes that did not have a clear initial 
relation to social impact measurement were temporarily set aside. This reduced the number of working codes to around 170 . Next, a fuller thematic analysis was performed to uncover second- and third-order linkages, commonalities, and more general, aggregate themes (Corbin \& Strauss, 2014; Van Maanen, 1979). Coding was mainly performed by one author, with the second author reviewing the coding for reasonableness and logic, while also acting as a devil's advocate and a sounding board. Codes and themes were reviewed and adjusted until agreement among authors was achieved.

As we analyzed our data, one foundational observation emerged that seemed to underlie much of the social entrepreneur's thinking about impact measurement: while social entrepreneurs were exposed to, and had sometimes attempted to some degree, many of the formal methodologies to measure social impact, social entrepreneurs almost never committed entirely to a specific methodology. Instead, social impact measurement was frequently more akin to a patchwork combination of elements from multiple methodologies. There were exceptions, as discussed in the findings, but once this general recognition was made, the preponderance of the rest of the codes organized into topics related to the thinking behind the social entrepreneurs' choices to create their own accounts of social impact rather than entirely commit to more formal methodologies. Built into their thinking, and the codes, were the inverse themes delegitimizing the reasons to pursue formal methods and legitimizing their alternative approach. All transcripts were then iteratively revisited, paying special attention to these themes, ensuring that all aspects had been captured and were understood. Figure 1 details the progression from first-order coding to second-level themes (Gioia, Corley, \& Hamilton, 2013), which then produce our aggregate understanding of how and why social enterprises delegitimized formal approaches to social impact measurement.

Insert Figure 1 about here

\section{Findings}

5.1 Reflexive accountability through formal social impact measurement 
Our interviews suggested that the social entrepreneurs in our sample were not consistently implementing any form of formal social impact measurement. Extant methodologies (e.g. SROI, logic models, or experimental methods) were essentially unused among social entrepreneurs in the small-tomedium sized enterprises that we interviewed. Only two of the twenty-two enterprises systematically used a formal methodology to understand their social impact. Five enterprises performed pilot testing or clinical trials to understand their product's performance and nine attempted some sort of survey, formal or informal, to gather baseline data. However, even when such data was collected, social entrepreneurs did not collect surveys both before and after the intervention to create structured preand post- intervention comparisons. Formal surveying was abandoned due to the high resource demands and limited applicability. Survey data that was collected was not processed into usable results using any type of formal methodology. Finally, when practices resembling a formal methodology were used, most interviewees, save those performing formalized engineering testing or medical clinical trials, readily admitted that their methods were inventions of convenience and imagination without any formal basis. The exceptions arose when the enterprise received funding from aid organizations or governments specifically demanding to evaluate impact in a specific manner; when the enterprise was developing medical devices that required specific proof of safety and effectiveness; or when a member of the enterprise's team had previously done impact measurement for another, larger organization.

We found that this absence of using existing methodologies was neither due to a lack of external stakeholder pressure, nor a lack of desire of the entrepreneurs. The interviewees explained that funders were interested in having formal measurements. While they might suggest specific methodologies, funders did not express a strong preference for the specific framework behind the impact measures, though, so long as it was perceived as sufficiently objective and evidence-based. Only the largest institutional and governmental funders requested specific units of measure or methodologies. All other funders seemed satisfied with the measures the social entrepreneurs had devised themselves. One social entrepreneur commented:

I think they just want to know where the money goes. No, we haven't really had anyone say, "We really want to have this specific metric met." Now, 
that's not going to happen in the future. I just haven't encountered it thus far.

While the social enterprises were subject to pressure to demonstrate their impact with evidence, they were still largely free to choose how. Yet, we also found that social entrepreneurs avoided existing methodologies. Instead, they frequently resorted to creating improvised collections of simple, ad hoc, self-generated methods, bricolaged together from at-hand data, experiential anecdotes, insights collected through encountered academic articles and collective industry wisdom from industry players (see section 5.3 below).

Several recurrent themes arose from the informants about the frictions that led them to eschew formal methods for social impact measurement. These ranged from concerns over counterproductive consequences of collecting impact data to those over the ability of impact measurement to accurately and sufficiently capture their social impact. These concerns were amplified by the challenges of implementing impact measurements and putting them into a comparable and contextualized format. The main arguments behind these sentiments are detailed in the following sections and summarized in Figure 1. Social entrepreneurs used these sentiments to critically engage with the formal social impact measurements they either encountered or that were suggested to them as ways to account for their social impact. Their critique not only highlighted several key concerns, but these concerns were employed to enable their use of an alternative, bricolage approach to constructing impact measurements that would better serve their needs and interests.

\subsection{Delegitimizing formal methodologies for social impact measurement}

\subsubsection{Social impact measurement as immeasurable}

A first critique employed to delegitimize social impact measurement methodologies was how social entrepreneurs portrayed social impact as immeasurable - both for them specifically and, more generally, for anyone. They frequently discussed how they lacked the capabilities and background to

perform such measurements. Their previous education and experience either did not expose them to methodologies for social impact measurement at all or at a level that would only remotely allow their use. For many of the social entrepreneurs, most aspects of business started as a blank slate: 
When you first foray in to this kind of market, everything is unknown and there is nobody to advise you. [...] Who are the stakeholders? Who's present? What's been done in the past? How has that worked? Has it worked or failed? All of these questions are a complete blank sheet of paper. You have nothing to go on that's been before.

This lack of exposure prompted entrepreneurs to search for existing resources. Many had engineering backgrounds and lamented how engineering programs lacked instruction in the business aspects they were dealing with, including impact measurement. They mentioned performing searches on the internet, discussing with partners or other social entrepreneurs who were also struggling with the same issues, and looking at case studies and academic articles. For those who searched heavily for impact measurement resources, the issue was never that they could not discover the existence of these methods; it was that they often did not have sufficient support and resources to implement them. Thus, even for those who actively sought out existing methodologies, these served as inspiration but were never formally implemented.

Besides, while funders demanded data and reporting, they rarely provided guidance or opinions on what needed to be collected or how to collect it. Funders either felt this was the responsibility of social entrepreneurs or lacked these capabilities themselves (Ebrahim \& Rangan, 2014). Social entrepreneurs also did not find existing industry standards or templates to follow. The examples they could gather from other social entrepreneurs tended to be very basic, specific to a particular organization, or tied to a particular funding source. This lack of standards led social entrepreneurs to construct measures that seemed relevant and appropriate to them, but also left many feeling quite uncomfortable with their metrics and not optimistic that better metrics were forthcoming. As one entrepreneur said:

I think another challenging aspect of, say, the clean cook-stove space, is that there aren't a lot of standards to compare against across geographies or across technologies. And I think that most of that implementing organizations or the product developers or manufacturers don't have the knowledge or the ability to assess these things.

Many stated that they would have appreciated greater guidance from their industry or from funders. Social entrepreneurs felt that neither they nor their funders had enough first-hand experience to generate projections that would hold up to scrutiny. Consequently, many enterprises delayed 
implementing any type of impact measurement, or relied solely on anecdotal evidence to account for their impacts: 'Yeah, I would say "sense" is probably a good word for right now because that's really the level that we're approaching the work.'

More generally, social entrepreneurs questioned whether it was even possible to generate accurate data. One issue that social entrepreneurs mentioned as a limiting factor for impact measurement was that the underlying data upon which metrics were built were inevitably unreliable and inaccurate. Many beneficiaries lived remotely or frequently moved, making it hard to locate and then reach participants to follow-up with them. Beneficiaries frequently could not be contacted without visiting them in-person. In many parts of the world, female beneficiaries were not permitted to talk to unrelated males without their husbands or another male relative present. Yet, these males were frequently away working for extended periods of time. Several entrepreneurs mentioned how gender and cultural norms also caused inaccuracies even when they could be reached. For instance, the presence of male family members was felt to bias and limit females' responses. Pride also played a role, generally causing beneficiaries to downplay the impact that an intervention had. For interventions that provided income or livelihoods to females, for example, entrepreneurs found that impact was downplayed or not acknowledged for fear of causing jealousy and resentment in male family members toward female income-earners. As one social entrepreneur mentioned: “[...] and there's the whole issue around 'my wife is making more money than me.' That is kind of frowned upon.” Discussing the impact of improvements derived from female income or products that primarily helped females could also bring shame and resentment to a family by implying that that a father or husband could not fully provide for the family. As another entrepreneur elaborated:

See, the thing is, all these things sometimes are also difficult to assess. This is something we can only guess at. Why? [...] People won't even acknowledge that their daughter's earning has made a difference for their household. For only some actually come out and say, well, you know that she has contributed to her brother's marriage or her wedding.

Conversely, and irrespective of gender, beneficiaries were suspected of withholding negative information or sugarcoating responses because they did not want to damage their relationship with a potential resource. 


\subsubsection{Social impact measurement as imprudent}

A second theme related to delegitimizing extant formal methodologies for social impact measurement was the cost and effort of gathering the additional data required for these methodologies. Implementing these methodologies was seen as an imprudent investment. While social entrepreneurs were motivated to measure social impact, they found that the demands of running their enterprise precluded them from dedicating time and money to such endeavors. For the emerging social entrepreneur, having impact was essential, but demonstrating impact was viewed as a burden on their time and resources. Social entrepreneurs instead focused more on providing details of impact as economically as possible to avoid distracting themselves from their goal of creating impact in the first place. As one entrepreneur stated:

One of the challenges as a startup social enterprise is that, it's not like we have a huge budget to invest in doing research. That's not our job. And so any research and data collection that we do has to be incorporated into our regular course of doing business.

Social entrepreneurs valued at-hand data, usually pre-existing marketing, design, or operational data, as the information upon which to build impact evaluations for its virtue of being free and not demanding additional time to collect. Attempting more formal methodologies often required additional data in order to adequately trace the causality of the changes in the situations of their beneficiaries. This data required time and effort to collect, e.g. via additional surveying or monitoring of the beneficiaries. Further, gaining sufficient data to ensure the validity of formal methodologies risked becoming quite significant investments - often requiring additional data both before and after an intervention, potentially on a large scale and over a long timeframe. Thus, the data required to adequately measure social impact seemed to far outstrip any slack resources at an enterprise's disposal. Unless external support was provided, impact measurement never became a sufficient priority compared to other demands on the enterprise. One social entrepreneur elaborated:

But no, we don't have a good sense and we're trying to figure out a way to monitor that. That's one of the challenges of being a social enterprise or social business is that first and foremost, we have to make sure that the business is working and that we're going to survive and that we're going to be able to continue operating. Figuring out how to measure impact, and when, is a secondary priority. 
Beyond the direct costs of trying to measure impact, additional indirect costs arose. Some social entrepreneurs reported that the process of collecting impact data caused their clients to change opinion about the goals of the social enterprise in ways that harmed their business. When social entrepreneurs surveyed clients to collect impact data, these were likely to interpret the surveys to mean that the social enterprise was actually equivalent to a non-profit. Social entrepreneurs suggested that their clients had never before experienced for-profits measuring impact; only non-profits seemed to do that. For the social entrepreneurs, performing surveys was risky because it could make their clients view them as non-profit organizations rather than as businesses, which made pricing their products or services more difficult. Clients' previous experience with non-profits was that non-profits either eventually gave products and services away for free or only charged a below-market token price. The social entrepreneurs worried that a perception of being similar to a non-profit would undercut their ability to set prices at remunerative rates.

Social entrepreneurs also emphasized that the costs of measuring data are born not only by those collecting it, but also by beneficiaries that have to provide the data. For the beneficiaries, providing data can be significant and negatively affect their livelihoods. Thus, the overhead costs of impact measurement imposed on an intervention's beneficiaries can counteract and diminish the net amount of impact generated. Some organizations chose to limit impact measurement to reduce the burden of collection, not on them, but on their beneficiaries. One enterprise described an extreme case:

We've had people who've come in and said, please call the women to the road head because I am not capable of walking. I do not wish to walk that one hour that it will take me to reach the village and talk to them there, so the women have to leave whatever they're doing, milking the cow or cutting the grass, and come and meet this great gentleman who has arrived from this one funding organization because he cannot be bothered to take the trouble. We refused to work with them, actually.

Thus, despite whatever value was to be gained from the collecting data that may lead to better decision-making, the costs in time, resources, and opportunity were often considered as an imprudent investment. 


\subsubsection{Social impact measurement as incomplete}

The third theme related to delegitimization that emerged from our analysis was that social entrepreneurs found that even if/when data could be accurately obtained, social impact data was fundamentally incomplete and could not capture the full import and complexity of their social impact. The insights social impact measurements generated and the conclusions they recommended were thus perceived as distorted and invalid. Metrics and measures were generally not considered being reflective of the situation on the ground. Part of the issue for social entrepreneurs was that metrics reduce the complexity and interconnectedness of their work. One entrepreneur explained how 'the parameters often themselves are not a good definition of how to evaluate. [...] Because the metric is trying to evaluate something intangible, so the metric is putting it into a structure, which is actually not possible.' Others talked about how there were too many factors at play, and metrics did not capture many of the relevant issues and ignored confounding or co-varying factors. Data could not reflect the complexity of the lives of the people they served and the environments they operated within. Social entrepreneurs discussed the multifaceted nature of the problems they and their beneficiaries faced. They were well aware of being just one small actor among many in a manifold and convoluted ecosystem. Trying to interpret their specific impact in isolation, or even reliably attributing causality from their specific outputs to broader changes in their environments was seen as an oversimplification of the dynamics and complexity of their environment. A persistent sense was that any sort of metric simply could not express enough detail to illuminate what was actually happening.

Social entrepreneurs argued that the effect of putting data into metric-based formats was that assessments inevitably either over- or under-estimated the importance of various factors and phenomena. Social enterprises that focused on more intensive, deeper solutions to poverty were frustrated, for instance, in how much weight and focus was put on the number of people helped, regardless of how significant the help provided was. A social enterprise that focused on housing found it very difficult to obtain funding due to the relatively small number of people affected, despite the substantial improvement provided to each person. The sheer number of people helped was frequently mentioned as a preeminent concern for stakeholders, regardless of the impact per person. Others 
mentioned how the impact measurements facilitated an over-emphasis on short-term over longer-term outcomes.

Timing was an issue because the timeframe required to make accurate assessments was quite long - generally years - and far longer than a social enterprise's timeframe to attract funding to operate and scale. They often needed to generate evaluations of impact to secure funding to operate and grow well before they felt the results of their operations had a chance to unfold. Social entrepreneurs detailed how they had to rely on a bevy of assumptions and projections to create pro forma impact measurements. Given the challenging environment, these assumptions were considered suspect and easily skewed. The social entrepreneurs explained how their practices, assumptions, and expectations were in a constant state of flux, as they continued to learn about their beneficiaries and environments. Even when social entrepreneurs had the opportunity to study impact over extended timeframes, they discussed how formal methods were impaired by environmental and cultural factors that led to low response rates, sample biases, and unreliable data. The settings they operated in simply did not allow for sufficiently complete or long-term tracking.

Several social entrepreneurs observed that oftentimes impact was generated for beneficiaries by preventing future costs or negative experiences, rather than improving their lives directly. Assessing these impacts imposes an even higher challenge, because impact would then need to be calculated by comparing beneficiaries' lives not against what did happen, but against what might have happened in a counterfactual world, absent the intervention. Particularly in tight-knit communities, improving an individual's outcomes often led to positive outcomes not only for that individual, but also for extended families, neighbors, and the larger community. The amount of impact detected could vary wildly based on where a social evaluation placed the artificial boundary of how far out to trace the ripples of an intervention. Likewise, many interventions also aimed to help an entire village or region, creating outcomes for communities beyond specific individuals. In these cases, the impact to entire communities or geographic regions needed appraisal, thus further expanding the complexity of impact measurement (Ebrahim \& Rangan, 2014).

Another common topic throughout the interviews was that funders and other stakeholders never actually visited the locations where the social enterprises operate. While impact measurements 
provided portable proxies for social impact, they also enabled key stakeholders to forsake actually visiting and observing the social enterprise and its environment. Without seeing the operation firsthand, most stakeholders failed to gain experience with the relevant context to truly understand the operation's details or to have their preconceptions and assumptions challenged. Social impact data was regretted by social entrepreneurs as a poor substitute for taking the time and effort to visit and gain an understanding of the operations in their local environment. Social impact measurements were also felt to reflect and reinforce Western cultural norms and preconceptions held by stakeholders rather than illuminate what was happening within the local environment the social entrepreneurs were working in. One social entrepreneur asked:

For example, how do you measure if a woman is empowered or not? [...] A village woman, for example, is expected to show her involvement in a very defined way, which is how an external factor would evaluate this as saying that, yes, in the community, all the women this organization is working with, are empowered because they behave in XYZ ways, one of which is a very, very vocal expression. For me, I find that kind of parameter very difficult to understand, because a woman in the mountains is empowered already, you know? She is the one who takes the burden of the society and runs this whole society here in the mountains, because the men don't work really. It's the women who are taking care of everything. So who am I to put a definition to her empowerment and for her to prove it to me?

Even with the best intentions of both parties, social entrepreneurs described how culturally influenced assumptions and preconceptions inevitably seeped into impact measurements, defining success according to Western norms and values. A similar concern arose when social impact measurements that had been created for much wealthier societies were adapted to use in extreme-poverty environments. Social entrepreneurs noted how this created measures laden with unworkable assumptions:

Questions around like, how many vehicles do you have? What group structure do you have? Like X, Y and Z type of thing. Some of them are kind of funny, because it's like, well, if you had any vehicle at all you almost wouldn't be asking the questions here. Some of the guys I work with laugh at them, not everything translates always here.

Another critique of formal methodologies is that they stripped out intuitive and emotional information. The entrepreneurs quite frequently found that non-rational and affective information 
played a strong role in stakeholder decision-making. Such information was felt to provide inspiration and motivation to act. Further, they described 'just knowing' impact, or that their claims made 'intuitive sense' even outside having details to substantiate. References to 'gut feelings,' 'instinct,' 'blind trust,' and intuition were prevalent as social entrepreneurs discussed how they knew the amount of impact they were having. Here, they appealed to how their knowledge of impact was embedded within the experiences and anecdotes they shared, i.e. their 'expert's intuition.' Such applications of expert intuition in decision-making have a well-established place in strategic management and have been noted as particularly useful and comparatively accurate in situations characterized by high uncertainty and a lack of available information (Hahn, Preuss, Pinkse, \& Figge, 2014; Jarzabkowski, Lê, \& Van de Ven, 2013). As one social entrepreneur commented, data 'doesn't really matter. The story is really what sells it, I think. And the story was conveyed with atypical information not usually included in impact measurements - images, anecdotes, intuitive senses, social media interactions, and affective reactions. People really understand that they accept the story, and I think that's a big draw.' Or, as another put it:

There are the SROI calculations and all that stuff that could come into it, but from what I've seen on a day-to-day basis or even from the feedback that we got from people that are there and doing that is that yes, that stuff is theoretical but at the end of the day there's also a gut feeling that goes with certain products and also goes with how you envision the entrepreneur and the organization or that what the organization is creating and what sort of faith you have in that in terms of momentum that's building too.

\subsubsection{Social impact measurement as irrelevant}

Even when impact assessments were created, a final theme related to delegitimization that social impact measurement provided little-to-no actionable insights. Social entrepreneurs thus considered social impact measurement as irrelevant. Even as progress was observed in some measurable way, there was generally no baseline or broader context to compare this progress against. Social enterprises could not objectively determine if the numbers represented marginal or groundbreaking success. Units of measure across projects were not consistent, and even when they were, social entrepreneurs pointed out that the environments - even village to village - represented different starting points and different levels of environmental munificence. This meant that even 
equivalent outcomes did not represent equivalent achievements. While they had anecdotal evidence and intuitive judgments of their ventures' success, translating these senses into comparable results was not possible. As one social entrepreneur concluded regarding attempts to quantify impact: 'They're not really giving you, statistically speaking, significant information.'

They particularly questioned whether the increased precision afforded by certain measurements would affect decision-making. The intuitive 'gut feeling' of impact, social entrepreneurs reflexively gained through experience, was generally argued to be sufficiently accurate. Finally, while funders wanted to see numbers, there was a sense that funders largely did not actually use these impact measurements strategically. Rather, the measurements had a more symbolic role signifying that the social enterprise was keeping stakeholders informed and updated, that it was thinking about impact systematically, and that it was transparent. Thus, the measurements themselves, and the validity of the methodology used, were considered less important. The creation of an impact measurement, then, was just as likely to be viewed as an artificial task done to appease funders as to be viewed as part of a program to gain usable insights:

You always need to state SROI, the SROI, the return of investment. We really tried to calculate, and I mean we came up with some kind of number, but that was, basically, you could have skewed that number. No one had noticed, I think.

\subsection{A bricolage approach to social impact measurement}

Interestingly, our data did not suggest that social entrepreneurs used the four delegitimizing critiques to avoid social impact measurement. The social entrepreneurs largely agreed with the purpose and goals behind social impact measurement and expressed a strong belief that measuring impact in a formal manner was important. They frequently conveyed hope to be able to invest more resources in developing more trustworthy and useful evaluations in the future. What we originally mistook as a lack of methodology among the social entrepreneurs was actually a competing approach to evaluation that forsook strict adherence to formal methodologies that focused on tracing a causal logic for a form of impact measurement that emphasized the value of opportunistically collecting at- 
hand, experiential data and ideas that might prove useful. That is, they actively created an alternative set of bricolaged impact measurements. As one social entrepreneur noted:

See, the thing is, we live here, right? We don't function remotely. We live and work in the same region, so our entire team is from this area, so the impact is not an external factor that you measure. It's something you can see.

Using the current and archival secondary data collected for each enterprise, we analyzed how social enterprises put forth information about their social impact to their current and prospective stakeholders. We found a pattern whereby social enterprises demonstrated their social impact through ad-hoc combinations of at-hand operational, design, and sales data; experiential anecdotes; retained highlights of academic research that they encountered; emotionally resonant images, videos, and other 'bric-a-brac remains' (Douglas, 1986: 67) of commonly accepted wisdom and assertions. Social entrepreneurs strategically chose which ideas about impact to include. For example, a social enterprise that focused on the deep impact of providing homes avoided defining impact in terms of scale. Table 2 provides an overview of these at-hand elements.

Insert Table 2 about here

The bricolaged measurements differ from formal methodologies in several respects. First, in formal methodologies, some, but rarely all, of the information listed in Table 2 is required as input data to calculate impact. These methodologies generally employ rules and standards on the data they utilize, excluding, for example, data that is overly subjective, unverifiable, or not relevant for its calculation. We observed that social entrepreneurs' bricolaged measurements rejected external limitations on what may serve as data, and included all at-hand information irrespective of the potential applicability or relevance to any pre-determined conceptions of social impact and its measurement. One social entrepreneur told funders:

If you want to understand, you'd better find the time to understand. If you've taken the time to give us money, then you come and take the time and understand what we are doing. This is what the foundations need to learn, no? Organizations always don't have to dance because somebody has given them money to work. I think there need to be more and more people saying 
no to this kind of way of functioning. Then it will change; because right now, it is foundations and investments that are driving it. There are a few people who are saying no, and the happy news is there are enough people who think like that, too, but a larger perspective that needs to change.

Individual data was presented either in isolation, or adjacent to, but independent from each other. Accounts generally failed to attempt to formally posit any causal relationship between the individual elements or otherwise organize the elements into a causal chain. For example, impact was sometimes simply demonstrated through pictures of beneficiaries using a social enterprise's products, accounts of satisfied customers, or copies of thank-you letters received. These were often combined with a detail about the performance features of the social enterprise's product and a factoid about the number of people in a country or region that might be suffering from the need the social entrepreneur's product addressed. If the product generated income or reduced expenses, the amount was always given, as was any time children were able to go to school, for example. However, how this information related to impact (or, sometimes even outcomes) was left to the imagination and common sense of the evaluator.

Those making evaluations were expected to make-do with this information to draw their own (individual or collective) insights from the data. Accounts did not reconfigure the data into an overarching framework or causal chain, but simply made do with the intuitive conclusions that arose from these thematic collections of facts. Social entrepreneurs, when they were motivated to attempt collecting more formalized measures (either due to pressure or their own internal desire for greater rigor), bricolaged ideas for how to do this from pieces of formal methodologies they had encountered. A social entrepreneur described the process of trying to determine some measures to collect, and whether to invent their own or use a formal methodology as follows:

Well, we do a little bit of both, but we definitely based them off of someone's work ... I mean, we're very small, so being able to leverage resources that other people have created is very helpful in certain aspects, especially this kind of stuff. We have some stuff that we use that we pulled off of ...It's one of the big ... It may be Acumen. Because, like I said, we modify them some, but they are based off of an established body of research, like an established way of doing that type of research and analysis. ... It's always a challenge with us, with the funding one, because doing those studies in a way that really is statistically significant is expensive, so yes, if we can leverage other people's work in terms of at least having a 
methodology for measuring that type of stuff, it helps.

Overall, we found that social entrepreneurs were not deciding upon an existing method and then attempted to collect the relevant data necessary to implement that method. Instead, they started with the data they have at hand and bricolaged it together into thematic bundles to see what kind of ideas regarding impact might arise.

Stakeholder power did significantly affect this process. Many large institutional and governmental funders have conditions for funding based on demonstrating impact in very specific ways. One interviewee shared her experience looking for additional growth funding via USAID. This funder requires social entrepreneurs to answer specific questions about their impact as part of the application and imposes the use of statistical analysis to quantify and then compare impact per dollar.' Because USAID is such a large and powerful funder, social enterprises that seek USAID funding must comply with such detailed methods for impact measurement. The social entrepreneur that found herself in this situation described her attempts to comply as much as possible. Still she expressed having little confidence in the numbers produced. As a result, some form of decoupling might be an issue in these cases (Bromley \& Powell, 2012). For most social enterprises in our sample, however, much of the funding came from funders with whom they could exert some interpretive flexibility regarding what types of impact measurements to use.

\section{Discussion and conclusions}

As noted in the introduction, the extant literature on social impact measurement highlights how the ambiguity around social impact and its measurement leads to frictions between the various different stakeholders involved in a social enterprise (Ebrahim et al., 2014; Ebrahim \& Rangan, 2014; Nicholls, 2009). Underlying these frictions is a conflict between what makes a social impact account valid and useful for stakeholders such as funders who operate from arm's-length, as opposed to social entrepreneurs whose daily lived experiences provide them with information unavailable to others. These various positions relative to the data, as well as each group's different interests, can cause frictions for what impact accounts are viewed as valid and useful. 


\subsection{Four lines of critique to delegitimize formal methodologies for social impact measurement}

This paper finds two interrelated mechanisms at play for how social entrepreneurs manage frictions amongst stakeholders regarding social impact measurement. First, social entrepreneurs use four lines of critique to delegitimize formal methodologies that involve evaluating the causal chain from inputs to impacts. Whenever social entrepreneurs sense that formal methodologies misrepresent or distract from their quest for social value creation or what they experientially know to work, they find important, social entrepreneurs attempt to resolve the tension by employing these four delegitimizing critiques aim to create voids of legitimacy in these methodologies - voids that provide social entrepreneurs the interpretive flexibility to blend in alternative forms of data and ideas. Second, bricolage is the mechanism social entrepreneurs use to fill the voids and create alternative accounts that fit their own understanding of social impact.

Insert Figure 2 about here

As seen in Figure 2, each of the four critiques reveals a different aspect of how social entrepreneurs' delegitimize formal methodologies for social impact measurement. The lines of critique expose the social entrepreneur's beliefs of what makes a good social account: i.e., validity (defined as the degree to which the data and underlying theory of the methodology correspond to the perceived reality of the social enterprise) and usefulness (defined as the degree to which the data and underlying theory of the methodology can guide decision-making). What makes a social account valid and useful is then considered at the material level (i.e., the nature and source of the data required for the methodology) and the ideational level (i.e., the theoretical logic underlying the methodology). Figure 2 shows how each form of delegitimization proffered by social entrepreneurs - i.e., immeasurable, imprudent, incomplete and irrelevant - focuses on highlighting a different purpose of social accounts that formal methodologies fail to meet in the social entrepreneurs' perception. By 
showing the data-related or theoretical voids in formal methodologies, the four critiques hinder the wholesale implementation of these methodologies and justify social entrepreneurs' interpretive flexibility to fill these voids with data and theoretical elements that social entrepreneurs prefer. While Figure 2 presents material and ideational bricolage as separate levels, this is only done for analytical reasons, as the evidence suggested that both forms of bricolage are inextricably entwined and thus ontologically co-constitutive.

At the material level, delegitimizing specific types of data used in formal methodologies enables ideational bricolage by impairing evaluators from committing wholesale to the methodologies that require such data. The immeasurable critique delegitimizes the data that formal methodologies require by arguing that the data is either inaccurate or impossible to obtain. The imprudent critique instead argues that the data collection is too costly in terms of resources and managerial attention, and that the process harms beneficiaries. Together, these two lines of critique challenge any methodology that depends on collecting highly prescribed data. In doing so, the social entrepreneurs create a void i.e., a lack of data to construct impact accounts following formal methodologies - which grants them the flexibility to propose alternative social impact accounts that can be constructed with data available at hand. Criticizing formal methodologies on the material level thus supports ideational bricolage because the social entrepreneurs can only make do with at-hand data by developing their own constructed methodology for social impact measurement, bricolaged from ideas drawn from their own experience or from ideas salvaged from the delegitimized formal methodologies.

At the ideational level, delegitimizing the specific theory underlying formal methodologies enables material bricolage by creating the interpretive flexibility to ignore limitations on what data can or cannot be used to measure social impact. The incomplete critique argues that the causal chain of formal methodologies does not do not represent the whole picture of a social intervention or all the confounding variables at play, and thus fails to create understanding of the full impact of the intervention. The irrelevant critique instead argues that the measures derived from a formal methodology are neither relevant nor usable to predict future success or guide which course of action a funder or social entrepreneur should take. Together, these two lines of critique challenge the causal chain of formal methodologies. In doing so, the social entrepreneurs create a void - i.e., a flawed 
theoretical logic of formal methodologies - which grants them the flexibility to replace or add new theoretical elements which call for additional information from underutilized, undervalued, or discarded sources, particularly the experiential data social entrepreneurs value for its holistic view and practicality of use. Criticizing formal methodologies on the ideational level thus supports material bricolage because it allows social entrepreneurs to work around rules and standards of formal methodologies about what data can or cannot be used according to their underlying theory.

Overall, the delegitimizing critiques we observed speak to many of the frictions that arise as social entrepreneurs critically develop social impact accounts that are valid and useful for stakeholders positioned both within and outside the enterprise's operating environment. The lines of critique were in part used to serve social entrepreneurs prior to the choice and implementation of a methodology for social impact measurement in attempts to fend off formal methodologies, saving them from practices which they feared would waste effort and resources that could otherwise support value creation. However, we also observed these critiques being used during and after the evaluation to justify adjustments, to abandon impact measurement practices, or to manage evaluation results that failed to reflect their own understanding of social impact.

\subsection{Contribution to theory}

While bricolage has been used before to explain social entrepreneurship (Desa \& Basu, 2013; Di Domenico et al., 2010; Mair \& Marti, 2009), we make three main contributions to the literature that further develop bricolage in this field. Our first contribution is in underlining how ideational bricolage is an essential element of social impact measurement, and particularly how material and ideational bricolage work together in an intricate fashion. Our findings show how social enterprises used elements of material and ideational bricolage simultaneously for the practice of social impact measurement (cf. Baker \& Nelson, 2005; Lévi-Strauss, 1962; Mair \& Marti, 2009). Many social entrepreneurs described how they hoped to satisfy themselves and their stakeholders with constructed accounts of their social impact that made-do with existing data. In doing so, they were primarily using elements of material bricolage by making do with the resources at hand (Baker \& Nelson, 2005). Simple availability became the main criterion for information to be included in the 
construction of social impact accounts, refusing formal methodologies' ideational limitations of what data was appropriate or not according to a priori theories of how to evaluate impact. If social entrepreneurs had information that they felt was important, the mere having of the information justified its inclusion because the information need not fit a formal methodology. This approach meant that the entrepreneurs allowed themselves to use previously underutilized, undervalued, or discarded sources of information (Desa \& Basu, 2013). However, the only way the social entrepreneurs could make do with at-hand data was by constructing alternative methodologies for how to build data into accounts of social impact that used or accepted that data. The findings showed that much of the information used for a bricolaged approach to impact measurement was similar to what was needed for formal methodologies. By letting go of the need to follow the rules and standards of formal methodologies, the social entrepreneurs constructed new conceptions of what social impact means for them and how it can be measured. Hence, they dissected and repurposed existing ideas about social impact to create new ideas of social impact and evaluation that better fit their specific business and context (Carstensen, 2011). By using bricolaged methodologies that take advantage of underutilized, undervalued, or discarded sources of information, they were also able to develop more creative accounts of their social impact as they combined different types of information in novel ways (Baker \& Nelson, 2005; Garud \& Karnøe, 2003). This particularly came to the fore in the social entrepreneurs' use of information of an experiential or intuitive nature, such as images and powerful anecdotes. By giving richer narratives a place in social impact measurement, ideational bricolage helped the social entrepreneurs blend their interpretations and priorities into the trend toward social impact measurement being more objective and evidence-based (see third contribution below).

The second contribution that we make with this paper is in uncovering the integral role that delegitimization plays in the process of ideational bricolage. As Baker and Nelson (2005) argue, a fundamental aspect of bricolage in an entrepreneurial context is the refusal of the entrepreneur to see resource limitations as a constraint for entrepreneurial action. Formal methodologies, to the degree that they define specific rules and standards which integrate ideas of what data to collect and what ideas to use to interpret it, represent ideational and material limitations on the social entrepreneur's social impact accounts. We argue that the ability to refuse these limitations specifically relies on a 
process of delegitimizing the methodologies that create the limits. As integrated systems, formal methodologies are resistant to attempts to bricolage additional or substitute elements because these new elements do not have a prescribed place or role within the formal methodology's theory of how to measure social impact. Ideational delegitimization shows how the formal methodology is actually flawed, thus creating voids of legitimacy within the integrated theory. These voids become the spaces in the integrated theory that bricolage can fill with the new data and ideas that otherwise would have no place in the system. Thus, delegitimization provides the interpretive flexibility needed to avoid simply accepting a formal methodology wholesale and instead demand that social entrepreneurs and funders search through the individual elements - the data and ideas - that the methodology has put together to see where the problem lies and bricolage a solution. Delegitimization atomizes the data and ideas within an integrated formal impact measurement system, breaking them free from their roles within the delegitimized methodology for use as elements to be bricolaged together, along with all the other at hand data and ideas about impact that never made it into the delegitimized methodology to begin with. The refusal to be limited by formal methodologies leads the entrepreneurs to critically enact their resource environment and thus potentially create something from nothing (Baker \& Nelson, 2005).

Our third contribution is in providing a theoretical explanation for how bricolage serves as a critical response to the increased use of performance measurement and reporting constructions from accounting and finance as part of the rationalization and marketization of the social sector (Brest et al., 2012; Ebrahim \& Rangan, 2014; Kroeger \& Weber, 2014; Nicholls, 2009; Rourke, 2014). We argue that bricolage serves as a mechanism for social entrepreneurs to redirect social impact measurement away from simply borrowing from accounting and finance, toward creatively blending elements from these fields with the social entrepreneurs' own ideas of impact rooted in their experience (Oswick et al., 2011). Formal methodologies represent a borrowing strategy as they mirror ideas from accounting and finance to create an objective measure and then systematize a combination of data and interpretive theory that traces a causal chain from inputs to outcomes and impacts (Ebrahim \& Rangan, 2014; Frumkin, 2003; Roche, 1999). This causal chain follows the optimization logics of for-profit businesses (Desa \& Basu, 2013), because it assumes that the more accurately a 
method describes and measures the causal associations between inputs, outcomes and impact, the more optimally it measures impact. However, such borrowing from external theories wholesale seems to lead to the frictions discussed in the literature review, because these theories may not be fully appropriate to capture impact in the social sector. As Oswick and colleagues argue, the solution to such 'problems will come from a shift from theory generation premised on a unidirectional process of borrowing to a two-way process of correspondence based on the notion of "conceptual blending", (2011: 318). Bricolage represents such blending, as it shows how social entrepreneurs take whatever they can from a formal methodology and see how it might be combined with other data and ideas into a new construction of social impact. Social entrepreneurs using bricolage use the same data and ideas that formal methodologies use (to the extent that they are at-hand), but instead of placing these in a causal chain, they simply create a collection of facts that are left for stakeholders to interpret. The data is positioned together but the overarching causal relationships are stripped away or left implicit. This switch from borrowing to blending counterbalances discussions how the imported ideas are similar and appropriate ('i.e. of one-way borrowing based on analogical resonance') with discussions how they are dissimilar and do not fit (i.e. 'two-way blending based on analogical dissonance') (Oswick et al., 2011: 318). The social entrepreneurs' delegitimization critiques serve to create this dissonance and thus become the mechanisms to assist their interpretive flexibility.

\subsection{Implications, limitations, and future research}

While our research focused specifically on social enterprises, the practice of impact measurement is by no means exclusive to social entrepreneurs. For-profit entrepreneurs, for example, increasingly consider their broader impact on society, which implies that the topic of how to manage social impact measurement is becoming increasingly relevant as well. Indeed, social impact measurement is becoming more mainstream across a broad range of ventures that seek to improve the transparency and breadth of their existing performance measures by adding data about their impact on society (Zahra \& Wright, 2016). Our theoretical insights based on entrepreneurs' use of bricolage for accountability purposes thus extend beyond the field of social entrepreneurship alone into the broader realm of corporate accountability more generally. With broader notions of accountability, stretching 
beyond financial performance, the degree of contestation of how to measure the impact of business on society will likely increase as well. That is, frictions between entrepreneurs and their stakeholders about the entrepreneurs' impact on society will become more universal. Hence, future studies could build on our insights by examining in what way entrepreneurs primarily driven by a profit motive use bricolage to navigate these frictions. We would expect for-profit entrepreneurs to also face challenges with measuring their impact, but in different ways than social entrepreneurs due to their higher degree of familiarity with formal methodologies to measure performance. Hence, they might also partially delegitimize existing methodologies, but instead choose different elements to use in their bricolaged approaches. From a more practical perspective, our work can also serve to guide any organization attempting social impact measurement. Our work shows how a bricolage approach can be an effective way to reduce frictions amongst stakeholders that adhere to different ontologies and epistemologies regarding social impact and its measurement.

Our exploratory study focuses its lens on social enterprises that were least likely to have available resources and capabilities to achieve objective measurements, because they were too small, too early in their development, or too resource-strapped. While looking at such cases can effectively magnify and highlight the frictions our work aimed to study, there may also be a lifecycle element in the types of methodologies social enterprises use as well as the motives behind using these. For earlier-stage social enterprises, more bricolaged approaches may be sufficient to be accountable to their stakeholders. Later in a social enterprise's lifecycle, though, different methodologies or deligitimizations may become more prevalent as their resource base increases. Moreover, as social enterprises scale up they are likely to start depending more on the larger impact investors such as USAID that exert more pressure on them to use pre-specified methods to measure social impact. Thus, additional research is needed to fully understand how an enterprise's size, age, and resources affect a social enterprise's ability to meet stakeholder expectations regarding accountability for their social impact.

As is the case in all interview-based methodologies, there is the risk of sample bias. Although we did not identify any factors that would lead to systematic biases, we acknowledge the distinct possibility that those social enterprises choosing to respond to our requests have different experiences 
or viewpoints from those that chose not to. Larger and broader studies across a wider grouping of social enterprises could go a long way to answer these questions. Likewise, in our study we developed our sample based on variations across several dimensions and looked for social entrepreneurs' commonalities and patterns in thinking about social impact measurement, despite their variation. While this approach is well established methodologically, it leaves unexplored why there are differences along the dimensions and the role those differences may play. A future study could develop additional insights by going more in-depth using a more homogenous sample.

\section{References}

Adamowicz, W., Louviere, J., \& Williams, M. 1994. Combining revealed and stated preference methods for valuing environmental amenities. Journal of Environmental Economics and Management, 26(3): 271-292.

Baker, T. 2007. Resources in play: Bricolage in the Toy Store (y). Journal of Business Venturing, 22(5): 694-711.

Baker, T., \& Nelson, R. E. 2005. Creating Something from Nothing: Resource Construction through Entrepreneurial Bricolage. Administrative Science Quarterly, 50(3): 329-366.

Battilana, J., \& Dorado, S. 2010. Building sustainable hybrid organizations: The case of commercial microfinance organizations. Academy of management Journal, 53(6): 1419-1440.

Brest, P., Katz, S., Peeler, H., \& Stangler, D. 2012. A decade of outcome-oriented philanthropy. Stanford Social Innovation Review, 10(2): 42-47.

Bromley, P., \& Powell, W. W. 2012. From smoke and mirrors to walking the talk: Decoupling in the contemporary world. Academy of Management Annals, 6(1): 483-530.

Carson, R. T., \& Hanemann, W. M. 2005. Contingent valuation. Handbook of Environmental Economics, 2: 821-936.

Carstensen, M. B. 2011. Paradigm man vs. the bricoleur: bricolage as an alternative vision of agency in ideational change. European Political Science Review, 3(1): 147-167.

Chen, H.-T., \& Rossi, P. H. 1983. Evaluating with sense the theory-driven approach. Evaluation Review, 7(3): 283-302.

Choi, N., \& Majumdar, S. 2014. Social entrepreneurship as an essentially contested concept: Opening a new avenue for systematic future research. Journal of Business Venturing, 29(3): 363-376.

Corbin, J., \& Strauss, A. 2014. Basics of qualitative research: Techniques and procedures for developing grounded theory: Sage publications.

Coyne, I. T. 1997. Sampling in qualitative research. Purposeful and theoretical sampling; merging or clear boundaries? Journal of advanced nursing, 26(3): 623-630.

David, W., \& Fahey, L. 2000. Diagnosing cultural barriers to knowledge management. Academy of Management Executive, 14(4): 113-127.

Desa, G., \& Basu, S. 2013. Optimization or bricolage? Overcoming resource constraints in global social entrepreneurship. Strategic Entrepreneurship Journal, 7(1): 26-49.

Di Domenico, M., Haugh, H., \& Tracey, P. 2010. Social bricolage: Theorizing social value creation in social enterprises. Entrepreneurship Theory and Practice, 34(4): 681-703.

Dolan, P., \& Kahneman, D. 2008. Interpretations of utility and their implications for the valuation of health. Economic Journal, 118: 215-234.

Donaldson, S. I. 2012. Program theory-driven evaluation science: Strategies and applications. New York: Routledge.

Douglas, M. 1986. How institutions think. Syracuse, NY: Syracuse University Press. 
Ebrahim, A., Battilana, J., \& Mair, J. 2014. The governance of social enterprises: Mission drift and accountability challenges in hybrid organizations. Research in Organizational Behavior, 34: 81-100.

Ebrahim, A., \& Rangan, V. K. 2014. What impact? A framework for measuring the scale \& scope of social performance. California Management Review, 56(3): 118-141.

Edmondson, A. C., \& McManus, S. E. 2007. Methodological fit in management field research. The Academy of Management Review, 32(4): 1155-1179.

Eikenberry, A. M., \& Kluver, J. D. 2004. The marketization of the nonprofit sector: Civil society at risk? Public administration review, 64(2): 132-140.

Emerson, J. 2003. The blended value proposition: Integrating social and financial returns. California Management Review, 45(4): 35-51.

Fisher, G., Kuratko, D. F., Bloodgood, J. M., \& Hornsby, J. S. 2017. Legitimate to whom? The challenge of audience diversity and new venture legitimacy. Journal of Business Venturing, 32(1): 52-71.

Frumkin, P. 2003. Inside venture philanthropy. Society, 40(4): 7-15.

Garud, R., \& Karnøe, P. 2003. Bricolage versus breakthrough: distributed and embedded agency in technology entrepreneurship. Research Policy, 32(2): 277-300.

Gioia, D. A., Corley, K. G., \& Hamilton, A. L. 2013. Seeking Qualitative Rigor in Inductive Research: Notes on the Gioia Methodology. Organizational Research Methods, 16(1): 15-31.

Gras, D., \& Mendoza-Abarca, K. I. 2014. Risky business? The survival implications of exploiting commercial opportunities by nonprofits. Journal of Business Venturing, 29(3): 392-404.

Haab, T. C., \& McConnell, K. E. 2002. Valuing environmental and natural resources: The econometrics of non-market valuation. Cheltenham, UK: Edward Elgar Publishing.

Hahn, T., Preuss, L., Pinkse, J., \& Figge, F. 2014. Cognitive frames in corporate sustainability: Managerial sensemaking with paradoxical and business case frames. Academy of Management Review, 39: 463-487.

Hanemann, W. M. 1994. Valuing the environment through contingent valuation. The Journal of Economic Perspectives, 8(4): 19-43.

Holma, K., \& Kontinen, T. 2011. Realistic evaluation as an avenue to learning for development NGOs. Evaluation, 17: 181-192.

Hubbard, G. 2009. Measuring organizational performance: Beyond the triple bottom line. Business Strategy and the Environment, 18: 177-191.

Jarzabkowski, P., Lê, J., \& Van de Ven, A. H. 2013. Responding to competing strategic demands: How organizing, belonging, and performing paradoxes coevolve. Strategic Organization, 11: 245-280.

Kroeger, A., \& Weber, C. 2014. Developing a conceptual framework for comparing social value creation. Academy of Management Review, 39: 513-540.

Lévi-Strauss, C. 1962. Savage mind. Chicago: University of Chicago Press.

Liket, K. C., Rey-Garcia, M., \& Maas, K. E. 2014. Why aren't evaluations working and what to do about it: A framework for negotiating meaningful evaluation in nonprofits. American Journal of Evaluation, 35(2): 171-188.

Lumpkin, G., Moss, T. W., Gras, D. M., Kato, S., \& Amezcua, A. S. 2013. Entrepreneurial processes in social contexts: how are they different, if at all? Small Business Economics, 40(3): 761783.

Mair, J., \& Marti, I. 2009. Entrepreneurship in and around institutional voids: A case study from Bangladesh. Journal of Business Venturing, 24(5): 419-435.

Mair, J., \& Martí, I. 2006. Social entrepreneurship research: A source of explanation, prediction, and delight. Journal of World Business, 41(1): 36-44.

McLoughlin, J., Kaminski, J., Sodagar, B., Khan, S., Harris, R., Arnaudo, G., \& Mc Brearty, S. 2009. A strategic approach to social impact measurement of social enterprises: The SIMPLE methodology. Social Enterprise Journal, 5(2): 154-178.

Millar, R., \& Hall, K. 2013. Social return on investment (SROI) and performance measurement: The opportunities and barriers for social enterprises in health and social care. Public Management Review, 15: 923-941. 
Mueller Hirth, N. 2012. If you don't count, you don't count: Monitoring and evaluation in South African NGOs. Development and Change, 43(3): 649-670.

Nicholls, A. 2009. 'We do good things, don't we?': Blended value accounting in social entrepreneurship. Accounting, Organizations and Society, 34: 755-769.

Olsen, S., \& Galimidi, B. 2008. Catalog of approaches to impact measurement: Assessing social impact in private ventures, Social Venture Technology Group Working Paper. San Francisco.

Oswick, C., Fleming, P., \& Hanlon, G. 2011. From borrowing to blending: Rethinking the processes of organizational theory building. Academy of Management Review, 36(2): 318-337.

Paton, R. 2003. Managing and measuring social enterprises. London: Sage Publications.

Power, M. K. 2003. Auditing and the production of legitimacy. Accounting, organizations and society, 28(4): 379-394.

Putland, C. 2008. Lost in translation: the question of evidence linking community-based arts and health promotion. Journal of health psychology, 13(2): 265-276.

Roche, C. J. 1999. Impact assessment for development agencies: Learning to value change. Oxford: Oxfam.

Rogers, P. J., Petrosino, A., Huebner, T. A., \& Hacsi, T. A. 2000. Program theory evaluation: Practice, promise, and problems. New Directions for Evaluation, 2000(87): 5-13.

Rourke, B. 2014. Philanthropy and the Limits of Accountability. http://kettering.org/wpcontent/uploads/Philanthropy-and-the-Limits-of-Accountability.pdf: Philanthropy for Active Civic Engagement (PACE) and the Charles F. Kettering Foundation.

Sandelowski, M. 1995. Sample size in qualitative research. Research in nursing \& health, 18(2): 179-183.

Sandelowski, M., Holditch-Davis, D., \& Harris, B. G. 1992. Using qualitative and quantitative methods: The transition to parenthood of infertile couples. Qualitative methods in family research: $301-322$.

Schatzman, L., \& Strauss, A. L. 1973. Field research: Strategies for a natural sociology: Prentice Hall.

Simon, H. A. 1987. Making management decisions: The role of intuition and emotion. The Academy of Management Executive (1987-1989): 57-64.

Toohig, J. 2007. Progress Out of Poverty Index: Training Guide, Vol. 7: 2008: Grameen Foundation.

Van Maanen, J. 1979. The fact of fiction in organizational ethnography. Administrative Science Quarterly: 539-550.

Weick, K. E. 1988. Enacted Sensemaking in Crisis Situations. Journal of Management Studies, 25(4): 305-317.

Yin, R. K. 2003. Case study research design and methods third edition. Applied social research methods series, 5 .

Zahra, S. A., Gedajlovic, E., Neubaum, D. O., \& Shulman, J. M. 2009. A typology of social entrepreneurs: Motives, search processes and ethical challenges. Journal of Business Venturing, 24(5): 519-532.

Zahra, S. A., \& Wright, M. 2016. Understanding the social role of entrepreneurship. Journal of Management Studies, 53(4): 610-629. 
Table 1 - Summary of Interviews

\begin{tabular}{|c|c|c|c|c|c|c|c|c|}
\hline Primary Product & Interviewee Title & Country & Industry & Founded & Employees & Location & $\begin{array}{l}\text { Founder } \\
\text { Origin }\end{array}$ & $\begin{array}{l}\text { Profit or } \\
\text { Non-Profit }\end{array}$ \\
\hline Textiles, Dyes & Founder and Chairperson & India & Textiles & 1996 & N/A & Rural & Native & $\begin{array}{l}\text { Sustainable } \\
\text { Nonprofit }\end{array}$ \\
\hline Water Delivery System & Co-Founder and President & Chile, US & Water & 2010 & 10 to 20 & All & Western & For-Profit \\
\hline Straw Bale Housing & Founder and CTO & Pakistan & Housing & 2005 & $>5$ & Rural & Western & $\begin{array}{l}\text { Sustainable } \\
\text { Nonprofit }\end{array}$ \\
\hline Solar Cookers & Co-Founder and CEO & China & Cooking & 2007 & 10 to 20 & Rural & Western & For-Profit \\
\hline Blood Transfusion Device & Founder and СТO & Ghana & Medical & 2011 & $>5$ & All & Western & For-Profit \\
\hline 6. Handicrafts & Founder and Creative Director & Nigeria & Handicrafts & 2009 & $>5$ & All & Dual & $\begin{array}{l}\text { Sustainable } \\
\text { Nonprofit }\end{array}$ \\
\hline $\begin{array}{l}\text { 7. Heat Packs for Premature } \\
\text { Infants }\end{array}$ & Co-Founder and CEO & $\begin{array}{l}\text { India, Kenya, } \\
\text { US }\end{array}$ & Healthcare & 2012 & $>5$ & All & Western & For-Profit \\
\hline 8. Small Good Distribution & Founder & $\begin{array}{l}\text { Mozambique, } \\
\text { South Africa }\end{array}$ & $\begin{array}{l}\text { Distribution / Small } \\
\text { Retail }\end{array}$ & 2006 & $>5$ & All & Dual & For-Profit \\
\hline 9. Fortified Rice & Co-Founder and CEO & Mali & Food & 2010 & $>5$ & Urban & Native & For-Profit \\
\hline $\begin{array}{l}\text { 10. Agricultural Products and } \\
\text { Consultancy }\end{array}$ & Communications Manager & Multiple & $\begin{array}{l}\text { Agriculture, Water, } \\
\text { Sanitation }\end{array}$ & $1982 *$ & $100+*$ & All & Western & Non-Profit \\
\hline 11. Chocolate & $\begin{array}{l}\text { Co-founder and Managing Director, } \\
2^{\text {nd }} \text { Managing Director }\end{array}$ & Belize & Food & 2010 & 5 to 10 & Rural & Western & For-Profit \\
\hline 12. Social Investment Fund & Senior Investment Manager & Multiple & Finance & 1991 & N/A & All & Western & Non-Profit \\
\hline 13. Solar Base Stations & $\begin{array}{l}\text { Co-Founder, Designer, and } \\
\text { Strategist }\end{array}$ & Tanzania & Energy/Solar & 2012 & $>5$ & Semi-Urban & Western & For-Profit \\
\hline 14. Chocolate & Founder and CEO & Liberia & Food & 2004 & $>5$ & Rural & Native & For-Profit \\
\hline 15. Sanitation Centers & Community Partnership Officer & Kenya & Sanitation & 2004 & N/A & Urban & Native & For-Profit \\
\hline 16. LPG Distribution & Founder and CEO & Uganda & Fuel & 2008 & 5 to 10 & $\begin{array}{l}\text { Semi-Urban } \\
\text { and Urban }\end{array}$ & Native & For-Profit \\
\hline $\begin{array}{l}\text { 17. Consultancy and } \\
\text { Business Incubation }\end{array}$ & Co-Founder and Executive Director & Multiple & Multiple & 2010 & 30 to 100 & All & Western & Non-Profit \\
\hline 18. Menstrual Cups & Co-Founder & Kenya & Hygiene & 2005 & 5 to 10 & All & Western & For-Profit \\
\hline 19. Solar Lamp and Charger & Founder and Executive Director & Tanzania & Energy/Solar & 2011 & 5 to 10 & $\begin{array}{l}\text { Rural, Semi- } \\
\text { Urban }\end{array}$ & Western & For-Profit \\
\hline 20. Electricity Solutions & $\begin{array}{l}\text { Business and Sustainable } \\
\text { Development Manager }\end{array}$ & Multiple & Energy/Solar & $2009 *$ & $\mathrm{~N} / \mathrm{A}^{*}$ & All & Western & For-Profit \\
\hline 21. Motorcycle Taxis & Co-Founder and CEO & Uganda & Transportation & 2010 & 5 to 10 & Urban & Western & For-Profit \\
\hline 22. Home Insulation & Co-Founder and CEO & Pakistan & Housing & 2007 & $>5$ & Urban & Native & For-Profit \\
\hline
\end{tabular}




\section{Figure 1 - Social enterprises responses to the frictions inherent in social impact measurement}

First-Level Categories

- Measurement numbers not accurate, but people do not notice

- Measurement numbers not accurate, easily skewed

- Culture issues / respondent pride prevents measurement accuracy

- Couldn't interact with female clients because male relatives were not around

- Measures do not obtain valid data

- Testing is difficult - people do not know/say what they want

- Measuring is difficult / measures require large studies

- Impacts difficult because intangible rather than usual tangible

- Measures require large studies

- Testing is difficult - people don't know/say what they want

- Social entrepreneurs don't have knowledge or ability to assess standards/measures

- Business/sustainability skills not taught in college

- Don't feel confident about measures

- College support disappears at graduation

- Onus on social organizations to measure

- Many partners not real partners, just donors

- Partners - need their help to measure

- Even basic knowledge and research not understood by community groups

- No preexisting stats

- Often a blank slate/start with little or no info - all up to you

- Experience over time is often only info source
Second Order Themes

Data inputs are inaccurate

Measurement difficult to do

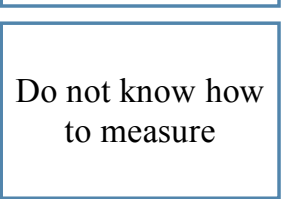

Partners can't/won't help when needed

No prior research, examples, templates
Aggregate

Dimension

Social impact measures as

Immeasurable

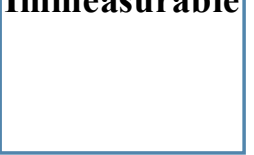

- Collecting data costs money, is expensive - don't want to add to overhead

- Don't have time/ money for studies

- Measuring difficult because lack of access to computer/internet/processing power

- Money is Tight

- Collecting Data Costs Money is Expensive, Don't Want to Add to Overhead

- Measuring Not Their Job, Not Where Want to Focus Time/Money, Lower Priority

- Financing Difficult for Businesses Because Startup Costs Extra Big for SE's

- Measures - Ask Too Much and People Think They Are Part of an Experiment

- Trials of Previous Iterations Can Cause Bad Word of Mouth for Future Versions

- Prior Overhyped Products Leads to Bad Word of Mouth

- Other's Prior Projects Failures Affects Community Perceptions for Your Project

- Profitability Needs Excludes Poorest

- Measurement Burdens Poor - Takes Away from Productive Labor

- BoP Avoid Products that Identify/Taint Them as Poor

- Focus on Quantity Causes Harm to Quality and Needed Training/Info

- When Investors Recommend Metrics, It Alters / Imposes Agenda on Or
Prohibitively

Costly / Time

Consuming

Takes Resources

Away from

Growing Business

Surveying /

Surveying

Negatively

Impacts Product

Measures Harm or

Shift Focus Away

from Most Needy
Social Impact

Measures as

Imprudent 
First-Level Categories

- Need a Long Time, Years to Really Understand Enough to Develop Product

- Customer Feedback/Testing Too Late in Process to Course Correct

- Iterating from Pilot Testing is Time Consuming and Expensive, Like Starting Over

- Testing Comes So Late in the Process that Most Facets Already Set

- Needs - Varies Among Individual's Identity/Role Within BoP Community

- Measures - Specific to Individual Projects

- Impacts - Different Value of Same Impacts Based on Position - BoP vs Non-BoP

- Unintended Consequences Always Happen

- Individual Impacts Also Affect Greater Community

- Impacts Not Seen Because Are Avoided Costs to Society

- Not Understand Causality That Leads to Impacts - Esp. Health Related

- Measures Ignore Complexity and Reduce Interconnectedness of Situations

- Parameters/Metrics Not Good Definitions of What Evaluating

- Metrics Do Not Reflect Reality

- Apply ToP Measures Inappropriately to BoP

- Scale Measures Give Larger Impact to Cheaper Inventions

- Investors Never Go to a Site, Not Really Get Community Context

- Measure s Not Integrated into National or Other Stats

- Investors Not Know What Really Happening

- Being in Different Geographic Region is a Big Barrier to Understanding

- Lack of Familiarity Means Don't Have Context for Knowing Value

- Parameters/Metrics Impose Western Definitions of Norms/Values

- Emotional Choices Drive Decision to Accept

- Data Doesn't Matter, Story Key to Justifying Impact

- Utilitarianism Theoretical, But Gut Instinct / Intuition is What Actually Used

- Don't Know Impact Details - It Just Makes Intuitive Sense

- Sometimes Just Blind Trust
Second Order

Themes

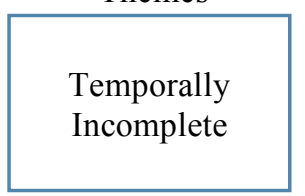

Granularity

Incomplete
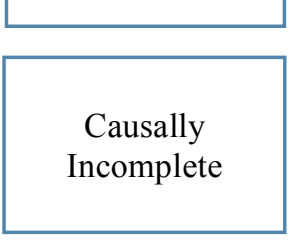

Definitionally/

Conceptually

Incomplete

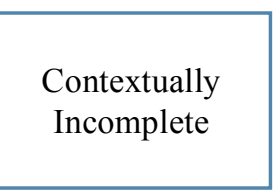

Emotionally Incomplete
Aggregate

Dimension
Social Impact

Measures as

Incomplete
- Measures Not Integrated into National or Other Groups Stats - No Comparability

- Lack of Standards Measuring Makes Serving BoP / Financial Supporter Difficult

- Any Prior Measures Are Specific to Individual Projects

- Investors not ask about Specific impact

- Impacts - Do Not Really Measure

- Orgs should ignore Measures, not focus on them, Investors will come if you are doing good things

- Don't Have to Justify Accountability to Anybody / No Institutional Mandate

- Utilitarian Models Too Complex

- People Disagree on What Leads to Highest Utilitarian Value

- Utilitarian Models Need Big Studies

- Utilitarian Models Not Only Measures of Success for Orgs Utilitarian Models Mainly

Used by Unsophisticated Investors

- Utilitarian Models Not Important/Considered

- Investors Simply Don't Ask for Metrics of Impact

- Investors Accept Whatever Metrics Measures Created by Organization

- Don't Have to Justify Because Investors Believe Same Thing You Believe

- Investors want mainly disclosure, to be kept informed and updated

- Investors want numbers -- any numbers

\section{No Common \\ Standards / \\ Practices for \\ Comparison}

Knowing Exact

Amount of Impact

Not Important

Utilitarian

Optimization

Not Possible

Specific

Methodology

Not Important 
Criteria for Good Social Impact Measures

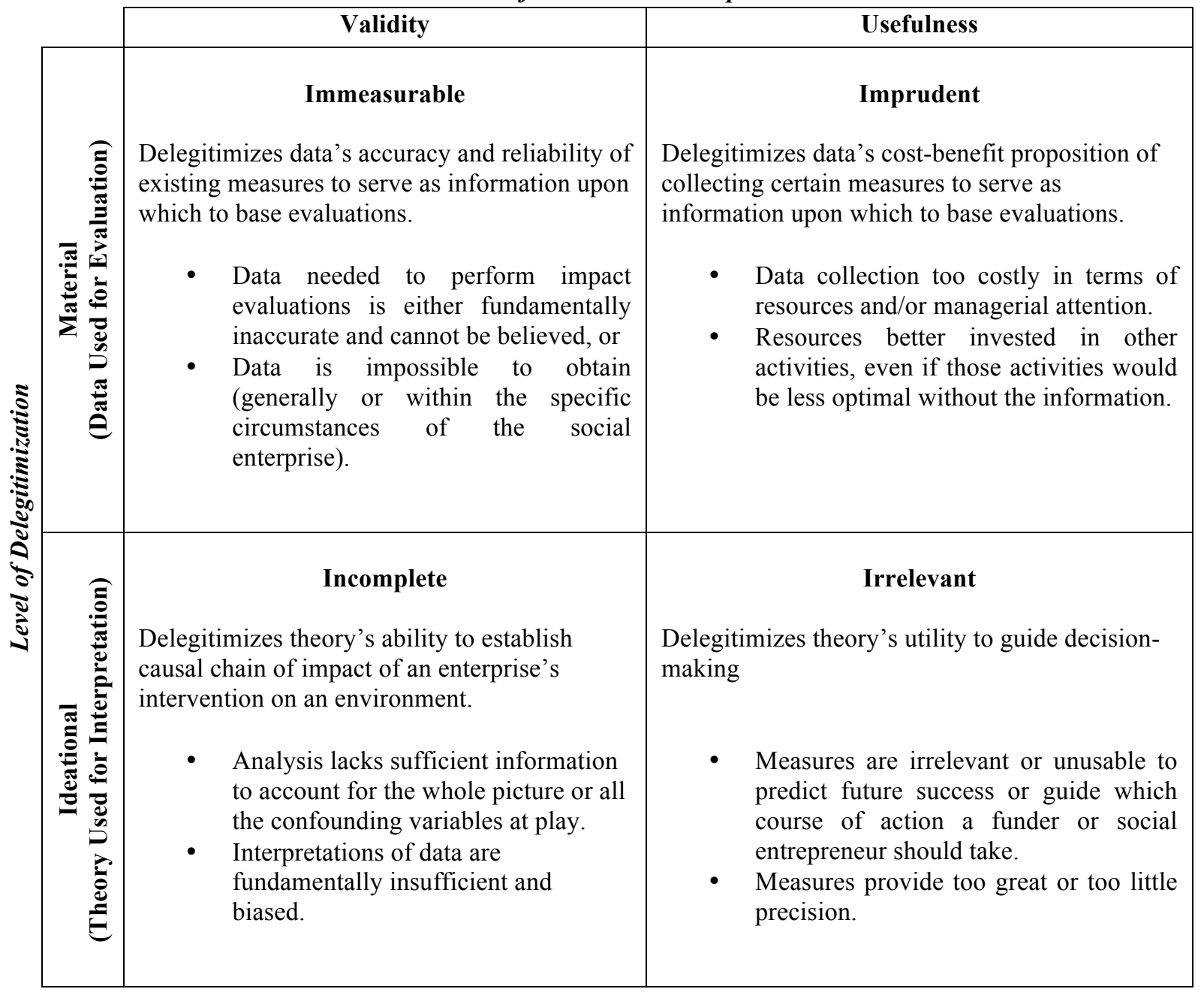


Table 2 - Common At-Hand Impact Elements Used in Bricolage

\begin{tabular}{|c|c|c|}
\hline $\begin{array}{l}\text { Measurement } \\
\text { Element }\end{array}$ & Description & Example \\
\hline Scale Indicators & $\begin{array}{l}\text { Indication of } \\
\text { number of people } \\
\text { impacted or } \\
\text { number of outputs } \\
\text { generated. }\end{array}$ & $\begin{array}{l}\text { From a local craftwork enterprise: } \\
\text { To date, [enterprise] has worked directly with } 106 \text { villages. We have } \\
\text { benefitted } 4,500 \text { people while indirectly impacting } 23,000 \text { people } \\
\text { through our various projects and activities. } \\
\text { From an enterprise shifting consumers from wood to gas cooking: } \\
\text { Since } 200 x \text {, [enterprise] has earned over } \$ 1.7 \text { million by building a } \\
\text { customer base of over } 4 \text { thousand families who, on average, save about } \\
25 \% \text { on cooking fuel costs. }\end{array}$ \\
\hline $\begin{array}{c}\text { Product } \\
\text { Design/Capability } \\
\text { Data }\end{array}$ & $\begin{array}{l}\text { Design } \\
\text { information that } \\
\text { shows capability } \\
\text { of product to } \\
\text { improve lives or } \\
\text { environment }\end{array}$ & $\begin{array}{l}\text { From a solar charging kiosk micro-enterprise: } \\
\text { 'Our public kiosks attract customers and creates a physical location for } \\
\text { additional retail product distribution and other business opportunities } \\
\text { such as: Secure storage for phones or additional products - The } \\
\text { Kiosk's Mobility allows it to locate strategically based on the market } \\
\text { needs - 50W Solar Panel (as roof) - } 20 \text { DC outlets for phone charging } \\
\text { - 34Ah of } 12 \mathrm{v} \text { battery storage' } \\
\text { From a solar cooking enterprise: } \\
\text { 'The cookware heats up } 5 \mathrm{x} \text { quicker than traditional charcoal. That } \\
\text { means you can start cooking faster. Zero toxic smoke and zero soot in } \\
\text { your food means healthy cooking. Zero carbon emission. } 100 \% \\
\text { recyclable. Engineered for a positive net impact.' }\end{array}$ \\
\hline $\begin{array}{l}\text { Identifiable } \\
\text { Personal } \\
\text { Connection }\end{array}$ & $\begin{array}{l}\text { Information to } \\
\text { identify and build } \\
\text { connection to } \\
\text { specific } \\
\text { individuals helped }\end{array}$ & $\begin{array}{l}\text { From a motorcycle taxi rent-to-own enterprise: } \\
\text { Five mini-bios of taxi drivers with pictures of each sitting on } \\
\text { enterprise's motorcycles. } \\
\text { From a chocolate farm for employing (previously unemployable) } \\
\text { former child soldiers: } \\
\text { A photo gallery of farmers at work. }\end{array}$ \\
\hline $\begin{array}{c}\text { Information About } \\
\text { Need }\end{array}$ & $\begin{array}{l}\text { Information to } \\
\text { describe problems } \\
\text { and needs } \\
\text { enterprise aims to } \\
\text { alleviate }\end{array}$ & $\begin{array}{l}\text { From a low-cost home insulation enterprise: } \\
\text { 'Freezing temperatures throughout the 5-month winter means over one } \\
\text { million Northern Pakistani households experience extreme winters" } \\
\text { From a low-cost incubator product: } \\
\text { '15 million premature infants are born annually. } 1.5 \text { million of these } \\
\text { premature infants die in resource-limited settings. Keeping these } \\
\text { infants warm would save thousands of lives; there is a } 28 \% \text { increase in } \\
\text { mortality and morbidity for every } 1^{\circ} \mathrm{C} \text { drop in infant body } \\
\text { temperature.' }\end{array}$ \\
\hline $\begin{array}{l}\text { Conjectured } \\
\text { Possibilities }\end{array}$ & $\begin{array}{l}\text { Assertions of ways } \\
\text { individuals might } \\
\text { suffer without } \\
\text { intervention, or } \\
\text { ways life might } \\
\text { improve with } \\
\text { intervention. }\end{array}$ & $\begin{array}{l}\text { For a bio-sanitation facility: } \\
\text { 'The facility will provide affordable and hygenic sanitation services } \\
\text { while also producing biogas for domestic use for nearby homes and } \\
\text { local hotels. The bio-slurry fertilizer it generates will be used for agro- } \\
\text { forestry and greening the community. The center will ensure that } \\
\text { human waste turns into wealth by generating gas through bio-digester } \\
\text { systems and by producing fertilizer.' }\end{array}$ \\
\hline $\begin{array}{c}\text { Representative } \\
\text { Outcome or Best } \\
\text { Outcome Achieved }\end{array}$ & $\begin{array}{l}\text { Specific stories of } \\
\text { how individuals or } \\
\text { communities } \\
\text { benefited }\end{array}$ & $\begin{array}{l}\text { For low-cost, reusable menstrual hygiene product: } \\
\text { 'This is [Woman's Name]'s Story' box with picture of woman and } \\
\text { scan of a letter the woman wrote telling of her experience menstruating } \\
\text { without menstrual hygiene products and thanking enterprise for their } \\
\text { product which changed her life. }\end{array}$ \\
\hline $\begin{array}{c}\text { Governmental, } \\
\text { Industry, or } \\
\text { Academic Data and } \\
\text { Research }\end{array}$ & $\begin{array}{l}\text { General data and } \\
\text { research findings } \\
\text { relevant for, but } \\
\text { not specific to, an } \\
\text { intervention }\end{array}$ & $\begin{array}{l}\text { From an enterprise that builds latrines: } \\
\text { We used data from the World Bank's Water and Sanitation Program } \\
\text { Economics of Sanitation Initiative } \\
\text { (https://www.wsp.org/content/economic-impacts-sanitation) in order to } \\
\text { estimate the average net annual savings per household achieved when } \\
\text { households purchase an improved latrine. }\end{array}$ \\
\hline
\end{tabular}

* These quotes were altered slightly to protect anonymity. 